\title{
Hypertext of Duysebek Nakipov
}

Aslan Zhamelevich Zhaksylykov ${ }^{1}$, Asemzhan Zhaparkyzy Zhaparova ${ }^{1} \&$ Ainur Serikbaikyzy Aitmukhanbetova ${ }^{1}$

${ }^{1}$ Al-Farabi Kazakh National University, Almaty, Kazakhstan

Correspondence: Aslan Zhamelevich Zhaksylykov, Al-Farabi ave., 71, 050038, Almaty, Kazakhstan.

Received: December 21, 2014 Accepted: March 25, 2015 Online Published: May 22, 2015

doi:10.5539/ass.v11n14p272 URL: http://dx.doi.org/10.5539/ass.v11n14p272

\begin{abstract}
In the given paper the aesthetic, stylistic, especially poetological features of D. Nakipov (famous Kazakh poet and writer) are studied, the main features of the author's discourse are also examined. They fit well within the parameters of postmodern literary techniques and style, for example: function codes and markers, symbolism, affectation syntax and quirky shapes, expressiveness and impressionism can be relegated. By analyzing the aesthetic component of the work, the characteristics of author discourse, conceptual characteristics and strategies of the author, there is the conclusion that the novel of D. Nakipov is a sample of postemodern hypertext literature in a new wave of Kazakhstan.
\end{abstract}

Keywords: Hypertext, fractal, puzzle, culture-rheme, marker, post-modernism, author's discourse

\section{Introduction}

Nowadays Dyusebek Nakipov is one of the largest and most successful creative figures in contemporary culture of Kazakhstan. The scale and diversity of his work attracted the attention of influential critics, researchers (Badikov, 2009, pp. 122-127).

In aesthetics of D. Nakipov (here aesthetics is spoken in the meaning of literary techniques, in fact the writer's post-modernist thinking exploits intension of desanctification, demystification of traditional values) element of text dominates, it is often the element of radically changed, syntactically transformed text. It is known that plot's internal engine is systematization of character's development in the aesthetics of realism. Modernism has already refused this principle, having suggested another structural paradigm - integrity forms not by character's movement, but by author's model of universe, wherein not infrequently, even decadence, decay of introverted beginning was such model. Post-modern went further. Element of author's discourse, text's demiurge or author-creator's strategy prevail completely and entirely in the aesthetics of realism. Philosopher Nurzhanov B. writes about this: "The concept of" text "(derived from it the notion of" context "," intertextuality "," hypertext ") becomes the central concept of post-modernism and post-modern aesthetics. Semiotic principles of textual analysis have become the dominant methodology of postmodernism. Art in this perspective is seen as a form of discourse that has its own rules, its grammar and syntax, its own system of signification (signification), their hidden assumptions and preconditions " (Nurzhanov, 2010, p. 34). Although literary character, model of the world still do exist in it, they lose their social value, they are not interesting as essence and objects, another element rules the roost, another power, and this is interior power of the text itself, constitutive intension of the author-demiurge. "In all studied work, N. K. Sarsekeev notes that not characters move the plot, but author's wordy play. Hence, spinning "literariness" of the author's image, which is responsible for main author's target convincing without homily, provoking a reader for co-creation, "thinking and conjecturing", "finishing design" of the text" - theorist L. V. Safronova writes (2006, p. 18).

Aspects that are important for understanding the aesthetics of postmodernism is that the word game in the world of text appears advantageous strategy that assumes the character of the structure-forming paradigm. "Permutations of the text - the interchangeability of parts of the text found in the literature of postmodernism (Borhes "Hopscotch", M. Pavic "Dictionary of the Khazars", "Eternity and a Day", "Bite angel" P. Krusanov). Permutation allows the reader to engage in active co-creation and at the same time emphasizes the possibility of multiple interpretations and finals fate of the characters, the story of intrigue"- emphasizes A. K. Ishanova (2008, p. 365).

\section{Method}

Before modernism and post-modernism, text in the world literature existed as means of embodiment, implementation, realization of the plot's word in art, movement of literary character (antropological principle) 
either way bears objective and subjective thought about universe. Ontological principle (cognition of internal and external, accumulation of knowledge) has not been changed in this aesthetics. Postmodern exceeds the limits of ontological beginning, for not cognition and experience accumulation are significant here, but ways of relativistic clinch in otherness, which continuously disintegrate into similar fractals. Implicit author and implicit reader of postmodern text are natural conditions of this relativistic discourse, where strategic aim is experience of otherness, namely existence. Post-modernistic text breaks the link with external reader, for his reader is virtual, relativistically is preceded in the continuum of times, where perusal (reconstruction) of allusions, euphemisms, symbols, hints and markers, metaphors - semantically encoded language of this art has already been done. With this correspondence to his (virtual) reader, maître's language complexity of postmodern can be explained.

"The Source of reader's activity is the very specificity of artistic creativity. Calculation on the reader may be unconscious, so it is organic, predetermined very communicative nature of art. However, many artists specifically comprehended the role of the reader in the creative process "- sums G. M. Muchnik (1995, p. 73).

Thus, implicit correspondent of the post-modernistic text is a virtual reader (recipient), who particularly participates not only in a text's reading, but also in its reconstruction, semantic reconstruction of signs and symbols, he is in the secret of allusions and codes of prefaced text. In the continuum of the context he is mirror reflection of an author-narrator, his text clone, he is associated with the spoken demiurge, who establishes stratification of symmetry and asymmetry law, scilicet reflection, doubling and multiplication of meanings. These inside relations between author-narrator and virtual reader whittle down the role of outer reader, abstract social environment, creating hermeneutic block between aesthetic world and society. Strengthening of the virtual dimension in the postmodern is stated by aesthetic theorists. (Nurzhanov, 2012, pp. 4-5). In traditional realism laws of reception (readability) for an author were compulsory, he aimed at openness of meanings, transparency of concept, optimality of correspondence, he wanted to be adequately understood, although he did not avoid complexity. Cognitive and sign-aesthetic lines in realism usually spoke about appeal to society, to reading public, even to potentially future reader. Postmodern aesthetic context is broader. On the material of the new literature of Kazakhstan writes Altybaeva S. M. about it: "Postmodernism as a specific and self-sufficient aesthetic phenomenon provides a great painter of genre and stylistic and conceptual freedom for the image of reality, interpreted in the broadest sense." (Altybaeva, 2009, p. 122).

As for text of postmodern, this is often multidimensional author's discourse, communicative space, which builds diverse hierarchical relationship with outer and inner reader. All is different in postmodern, an omniscient demiurge of text requires enlightened reader, if he does not exist, he models him in the text, deriving of himself, cloning, this way implicit reader comes into existence. Therefore, hermeneutic decoding becomes reception condition of postmodernistic text, where reading of inter-texts, reminiscences, mythologem and culture-rhemes, symbols is possible only in the temple of particular religious knowledge, whish lives mainly in the sphere of meta-text and diachrony of art and philosophy. Therefore, symbols, tropes, markers, poetic figures, changed micro-text become major component of cognition in postmodernistic texts, which as if pointers and codes on the walls of labyrinth, lead to sanctum sanctorum of this world, otherwise to existence, which itself is notional core of continuum, or candlemas of associative conjugation of meanings.

It appears that, in the process of postmodernistic text creation, author's consciousness turns out relativistically involved in associative, allusive context world of the world word art or even art system to create cloth of guiding thread (signs and symbols), and only then of inertia dialogic niche with society, with outer recepient left. Apparently, such sign-symbolic, layer-specific use of culture-rhemes is inevitable, it is clearly observed from James Joyce ("Ulysses"), till D. Updike "The Centaur", V. Pelevin ("Chapaev and Void"). Complicated intercultural or cross-cultural diffusivity of textual, aesthetic world of postmodern, its characteristic feature, recipient's awareness are inevitable conditions of an adequate reading.

Similar diffusivity, to the full, inheres texts of Duysebek Nakipov, one of the sign post-modernistic writers of contemporary Kazakhstan. Numbers of arts, particularly, ballet and pictorial art, appliqué and music, decoration, sculpture and poetry are dialogically met in his dilogy "Circle of Ash" and "Shadow of Wind". Author's intention is an important concept of modern literary criticism. (Temirbolat, 2011, p. 75). As you know, intentional, creative energy of the author gave great importance to Heidegger. On this occasion, Zh. Baimukhambetov writes: "Of course, that for Heidegger the author's presence in creation can not be doubted, but his creation the author appears as if the role of Hamlet's father. He, being completely ghostly creature nonetheless inseparable from the events that take place in reality they described. In fact, Heidegger, pointing to a common identity of all creatures to one source, thus evinces confidence in ecstatic body of the author, the body, which gives things their unchanging attributes: weight, weights, ways to implement these or other movement" (Baimukhamedov, 2004, p. 81). 
In any of these arts, the author feels himself freely, easily, discovering deep knowledge, surely, especially in ballet, music and poetry. This is not happenstance, for D. Nakipov is famous in his time ballet dancer, later on director of the Ballet Theatre, therefore, a person able to read ballet music. Postmodernism in the contemporary literature of Kazakhstan - a recognized fact studied by critics and literary critics (Ananeva, 2009, p. 328). Undoubtedly, one of the brightest representatives of this new direction is D. Nakipov.

In recent 20 years D. Nakipov has expressed himself as wide scale poet, author of many poems, some of them became libretto to ballet settings. D. Nakipov's intellection seems unlimited in the sphere of World Arts, including sphere of masterpieces of the world prose. D. Nakipov's transformation into a novelist of postmodernistic direction seems natural and inevitable, for he is not a historian of Art and a chronicler, a fortiori not a novelist. Strategy of an author-narrator is creating maximum symbolic, complex and chamber-elegant and whimsical canvases of prose, not only for great reproduction of his own Word to the whole world, but also for the sake of own universe of the word. Energy of his accumulated intension and inter-texts is quite sufficient. "Perhaps, apocryphal (sacral, mystic) task of oeuvre is in taking existence appearing in alive, throbbing condition and conceive it again in metaphysical womb. But it is unknown for the author what a complete Word can be born out of this "black box". Therefore, nerve-text artistically "by Nakipov" collapses in the dylogy... this way E. Ismailovich characterizes writer's style (Ismailovich Unit, 2009, p. 5).

However, the author as an aesthetic authority in the text - the phenomenon is absolutely paradoxical, the more it overcome the human, personal, subjective, more productive for text than "transparent" and the integrity of its essence, the fuller its existence, the more fused with the impersonal continuum the more informative. It is legitimate and such treatment as the author in the text:

And perhaps, even so, that is not the author writes something, but something says (to be) through it. Authorship is not depends on the person, is a condition in which a man must empties. Through some "holes" of the space ideas master man (Ortega). Authorship - means or method, to whom the world over me. Paradox. This would seem to me that I want, I'm writing, but no, I did not write. Moreover, in the highest degree the author writes freely when he writes reluctant "(Kolumbaev, 2002, pp. 8-9).

Nakipov's reminiscence, taken from the pages of different genres or World Art, serves not only for depiction of ballet scene, backstage life of theatre, pastel sketching of the most intimate and privy sufferings of ballet dancers (of a Ballerina), but for particular correspondence with symbolic layer of meta-text, where generalization of hermeneutic meanings happens. This is refined staging of culture-rhemes, creation of polysyllabic puzzle, mosaic cloth, which meaning is only understood by text's demiurge and implicit reader. Consequently, the author does not care about integrality of both text and all architectonics, in the second part of the dylogy narrative layers (narration about cannibal, about wiseacre-hermit, about great conqueror) almost do not intersect in the plot, they develop in parallel, only semantically shade each other. Reading of their informational content is trusted to an implicit reader. "Referent of a literary text is within the text, rather than outside it. Artistic text is autoreference. Referent of a literary text, it signified the actual built in the reader's mind "- says K. K. Ahmedyarov (Akhmediarov, 2002, p. 77).

\section{Results}

The main plot nerve is simple and clear, it is love story of ballerina and Gevr. Unlikely, it demanded such compound, multipronged postmodernistic narration, except for the most important task, which stood before the author; the task was presentment of theatre life, ordinary, inescapable backstage world with its intrigues, shady enterprisers, and world of spirits behind astral contour of the ballerina, where demiurge of art is hidden, muse itself, great spiritual hypostasis of the Ballerina. Ballerina's motion to Goddess, her spiritual development and climax merger with her in the main dance is inner covert plot of the work. Movement of inner and outer plot is organized by gradation of symbols and signs, here all immeasurable chamber, texture of the superfine and unusually ductile and sophisticated descriptions is expanded. Impressionistic expressiveness of Nakipov's language manner, effect of three-dimensional visuality of images, bright expressiveness of phrases, multitone, figures, overflowing one into another, paradoxical, perhaps, are the strongest sides of his literary techniques.

"All recent years, par excellence that he completed his dancing life, from the first film with the participation of Ornello, Doka has gained her in the name of eidolon-goddess-angel-dream woman. This is contour-oval-moon-sunfaced imago, which is incomparable, superior all antique characters and images of revivalist Madonnas, somehow magical, fluorescent, incessantly changed, like surface of peaceful back-water under the crown of silver willow, crazy greenness of eyes, like a wild lynx has, with clever naturally pure eye shape and squint, which were ceaselessly contradiction-harmony with meek smile and full-luscious-explosive contour of lips, this dazzling-niveous-sudden-riviere number of teeth and killing-inviting nick between the upper 
teeth, amber-hot-unstoppable waterfall of hair, washes her neck, her neck is from flexible-light-bright china or ivory, which has soft and gentle elasticity of skin, as if it pearl comes to life! - all this is perfect splendor of unfeigned woman, crown of creation of Ornello! - she took him captive of inscrutable admiration-longing-aesthetic climax-insight". (Nakipov, 2010, p. 132).

\section{Discussion}

Here in the real verbal, phonetic sound-palette, the artist as if is unrivalled. At the same time, the writer is able to convey a complex range of layered experiences, often steeply banked in the astral (exorbitant) visions, hallucinations, dreams, subconscious feeling, where, however, plasticity and objectivity confidently retained. It must be admitted that, many years of experience of a great poet, master of words affects here. Narrative plan, dedicated to the life and work of a genius artist S. Kalmykov, borderes on the astral plane - a tale about the life of alien beings - samions, these two planes interpenetrate, semantically mutually dependent on each other. It is clear that bizarre samions are images generated by the artist's imagination, artist-character, videlicet S. Kalmykov. The history of the artist, life of his soul and tale about his spiritual incarnation - grandmaster - a reference to the fact that in the mid-20th century, one of the great avatar of art lived near us. Therefore, it becomes clear his huge impact on all the artists depicted in the novel, especially on the ballerina.

Postmodernistic text can not do without the energy of love. This is a special theme of the novel D. Nakipov. Characteristic feature, once fixed by theorists of postmodernism (Badikov, 2009, p. 56), herein fully confirmed by emotional, motive suggestive qualification of the work. (Safronova, 2006, p. 32, 56). Eroticism in the novel has dominant and pervasive character, often getting vernacular design. It can be assumed that there is too much going on, both in the first and in the second book of the dylogy. It appears that the beginning of the Dionysian dominates in the novel of D. Nakipov. There is a clear dissonance between high up, almost divine love between the dancer and Gevra and plan of physiological descriptions hypertrophied by sexuality of mythical Osmihorr in the first book and sexual maniac man-eating Bastard in the second book of the dylogy. The nature of this plan does not give confidence that the given dissonance has functional character, resulting from the strategy of the author-creator, gives general sense to the whole architectonics of huge novel. Eroticism clearly gives some alarming to the whole narrative canvas. Samions live in dismay, frightened by Osmihorr's unbridle character and Bastard's anxiety is transformed into a very real inferno, in which the chimerical character lives, gradually turning into a monster of the underworld, devoid of all human qualities, a sort of the Minotaur. It's dark in the first book, and quite black emotional background in the second book, wraps pastoral light stream - a tale of divine love between Ballerina and Gevra. Literary criticism, among other things, fixed, that the image of emotional state voltage requires aesthetic maximum from an artist. (Savelyev, 1999, p. 194).

This bright, creative, truly human flow in the novel is the pillar nerve of the work, it saves everything, real, perceived energy is built on it - moral stream, humanism, the tale of how human love gradually grows, turning everything around in warm, sunny colors. All the excesses of the novel, including style (Dzholdasbekova \& Sarsekeeva, 2013, p. 184), is redeemed by this piercingly bright and at the same time emotionally powerful flow of expressive and fine plan. In the concept-sphere of the work, this basic conflict of theatrical novel performs hidden feature, it displays the dance of lovers, as on the scene. On this stage, Ballerina and Gevra perform difficult part - the duo of almost plastic embodiment, dialogue, where words are often unnecessary. There body language and signs, hints, subtle movements, attitudes, guesses, intuitive understanding of mental comprehension and penetration prevail, it's almost telepathic language that can only exist between truly divine lovers. The joy of daily communication and increasing happiness of Gevra heal him from a terrible trauma - he drove into the subconscious memory the death of his wife and child in the crash of an airliner. He drove it so deep that there seemed no reflection, even memories, but there is a dark monster lurking - pain of mortally wounded psyche. Gevra would be doomed if it had not been a balley-dancer. With the help of her love and talent of finely tuned, tactful, gentle soul she heals him, revives for new life. Narrative fabric of the ballerina and Gevra passing through both books, the moral energy of truly renewing and life-giving force, the best song of polyphony in the huge novel, a duo of two voice, which spiritualized, became cleaner and heartier, the voice lifted to divine heights in the chorale. The tale of the ballerina and Gevra has potentially enormous moral power, and it acts on the reader's soul, fulfilling its eternal saving function of catharsis. Polyphony is quite natural for theatrical novel describing the music, chant, let it not even classical polyphony functional point of view (Uspenskaya, 2005, p. 21).

\section{Conclusion}

It appears that D. Nakipov managed to create the first multi-faceted theatrical romance in the literature of the new wave of modern Kazakhstan with an unusually complex neuro-pulsating, impressionistic shaped cloth. By 
his stylistic, aesthetic, contextual parameters, it is quite postmodern work. This is a very complicated text fabric acts as a hypertext, woven from a huge number of microtexts, intertexts, reminiscences, allusions with localized themes and sub-themes and general conceptual plan. Introverted character and plastic expressiveness of these texts are not in doubt.

\section{Acknowledgements}

Separate fractals of this large fine plan: the tale of a cat ballerina, about fish in an aquarium, about Gevra's panel, about application, which was made of fluff by Ballerina, about her pregnancy, about Gevra's earnings, about Kalmikov's pictures - it is very clear scenes to the reader, filled with life, good energy, uplifting power, drawn by a cutter of a confident master. These texts, micro-scenes, sometimes spontaneously turning into choreographic mise-en-scène, variety show, in the form of words seem quite independent impressionist paintings, and they create complex, ornamental expressive, quirky, filled with music space of ballerina and Gevra - the world of dance, the Bolshoi Ballet, which was skillfully transferred into the space of prose by the poet, theater director of the ballet, D. Nakipov. In this regard, the master managed to do his the most important task.

\section{References}

Akhmediarov, K. K. (2002). Linguistic poetics: tradition and innovation (p. 234). Almaty: Kazakh University.

Altybaeva, S. M. (2009). Kazakh prose during independence period: tradition, innovation, and prospects (p. 352). Almaty: KazNPU named after Abay.

Ananeva, S. (2010). Russian prose of Kazakhstan (p. 356). Almaty: Silk Way.

Badikov, V. (2009). The book about myself and about all (p. 288). Almaty, Idan.

Baimukhamedov, Zh. (2004). Truth and creation: Heidegger's original topology. Tamyr, 4(14), 76-83.

Dzholdasbekova, B., \& Sarsekeeva, N. (2013). Author's discourse of U. O. Dombrovskiy's prose in the context of modern Kazakh prose about the artist (p. 184). Almaty: Kazakh University.

Ishanova, A. K. (2008). Poetics of literary game (p. 400). Astana: Kultegin, ENU named after L. N. Gumilev.

Ismailovich Unit. (2009). Arabesque-break-point-beginning. Literary Gazette of Kazakhstan, 35(47), 5.

Kolumbaev, B. E. (2002). Authorship as a metaphysical problem. Fiction and problems of antropology. Karaganda: KarGU named after E.A.Buketov.

Muchnik, G. M. (1995). Problems of communicative poetics (p. 181). Almaty: Al-Farabi KazNU.

Nakipov, D. (2010). “Circle of Ash” (novel-dylogy) (p. 132). Almaty: Saga.

Nurzhanov, B. (2010). Modernist art, postmodern aesthetics. Tamyr, 1(25), 31-36.

Nurzhanov, B. (2012). Postmodernism and new media (computer and internet). Tamyr, 2(21), 3-10.

Safronova, L. V. (2006). Postmodern literature and contemporary Literary Studies of Kazakhstan (p. 96). Almaty: KazNPU named after Abay.

Savelyev, V. V. (1999). Art anthropology (p. 281). Almaty: AGU named after Abay.

Temirbolat, A. B. (2011). Poetics of literature (p. 168). Almaty: Kazakh University.

Uspenskaya, B. A. (2005). Semiotics of Art (p. 360). Moscow: Languages of Slavic culture.

\section{Copyrights}

Copyright for this article is retained by the author(s), with first publication rights granted to the journal.

This is an open-access article distributed under the terms and conditions of the Creative Commons Attribution license (http://creativecommons.org/licenses/by/3.0/). 